University of Nebraska - Lincoln

DigitalCommons@University of Nebraska - Lincoln

Norman R. Simon Papers

Research Papers in Physics and Astronomy

2-15-1983

\title{
The Structural Properties of Cepheid Velocity Curves
}

Norman R. Simon

University of Nebraska-Lincoln, nsimon@unl.edu

Terry J. Teays

University of Nebraska-Lincoln, tteays1@jhu.edu

Follow this and additional works at: https://digitalcommons.unl.edu/physicssimon

Simon, Norman R. and Teays, Terry J., "The Structural Properties of Cepheid Velocity Curves" (1983).

Norman R. Simon Papers. 18.

https://digitalcommons.unl.edu/physicssimon/18

This Article is brought to you for free and open access by the Research Papers in Physics and Astronomy at DigitalCommons@University of Nebraska - Lincoln. It has been accepted for inclusion in Norman R. Simon Papers by an authorized administrator of DigitalCommons@University of Nebraska - Lincoln. 


\title{
THE STRUCTURAL PROPERTIES OF CEPHEID VELOCITY CURVES
}

\author{
Norman R. Simon and Terry J. Teays \\ Behlen Laboratory of Physics, University of Nebraska-Lincoln \\ Received 1982 June 10; accepted 1982 August 5
}

\begin{abstract}
Fourier decompositions are performed on the velocity curves of 11 classical Cepheids. The progression of curve shape with period is described in terms of combinations of the lower order Fourier coefficients. These quantities are shown to change with pulsation period in a manner similar to that already demonstrated for Cepheid light variations (Simon and Lee). We recommend further velocity observations, particularly in the period range $10 \leqslant P \leqslant 16$ days.
\end{abstract}

Subject headings: stars: Cepheids - stars: pulsation

\section{INTRODUCTION}

Recently, Simon and Lee (1981) reported on the Fourier decomposition of the light curves of a large sample of classical Cepheids. It was demonstrated that combinations of the low-order Fourier coefficients could be used to describe quantitatively the progression of curve shape with period. In the present investigation we use the same technique to treat Cepheid velocity curves. Because of the relative paucity of velocity data, our sample in this case consists of only 11 stars whose velocity curves, and thus Fourier decompositions, are generally less accurate than were the light variations. Nonetheless, we shall be able to see in the velocities a progression very similar to that found for the light, including the sharp break at $\sim 10$ days characteristic of the Cepheid resonance (Simon and Schmidt 1976).

\section{THE FOURIER DECOMPOSITIONS}

Our fitting scheme is described by Simon and Lee (1981). For the velocities, we fit to a different form of Fourier series, viz.,

$$
v=A_{0}-A_{i} \sin \left[i \omega\left(t-t_{0}\right)+\phi_{i}\right],
$$

where, for a given fit, the index $i$ runs from 1 to $i_{\max }$. In the present investigation, $i_{\max }=4$ or 8 . Criteria for the sufficiency and appropriateness of the fits are as given by Simon and Lee (1981). However, because of the small sample of velocity observations, a number of fits that would have been considered marginal according to Simon and Lee (1981) have been accepted here.

Following Simon and Lee (1981), the time $t$ in equation (1) is used in the form

$$
t=\mathrm{JD}-\tau,
$$

where JD is the time of the observation in Julian days. The quantities $\tau$ and $t_{0}$ (eq. [1]) are constants in the fit.
Table 1 lists the stars whose velocity curves we have studied. References to the observations and to the values of $\tau$ are given in the "Source" column. Other columns give the period, observed amplitude, the number of observed points presented to the fitting routine, the order of the fit (i.e., $i_{\max }$ ), and the standard deviation. As explained by Simon and Lee (1981), the periods listed in Table 1 should not be considered definitive.

The Fourier coefficients $\left(A_{i}, \phi_{i}\right)$ up to fourth order, as well as the quantity $t_{0}$, are displayed in Table 2. For those stars with observations from more than one source, the data were combined as follows. First, each set was presented separately to the fitting routine and its zeroth order (i.e., unperturbed) velocity determined. This quantity was then subtracted from each observation before the different sets were put together for analysis.

The footnote " $b$ " in the first column of Table 2 indicates that an eighth-order fit was constructed for the corresponding stars. The additional coefficients for these cases appear in Table 3. The footnote "a" in the first column of Table 2 indicates a marginal fit in the sense that coefficients of order higher than two should not be considered fully reliable. These coefficients have been included merely for completeness. The coefficients of first and second order, on the other hand, are acceptable. It is these coefficients that shall interest us in what follows.

For the light curves in Simon and Lee (1981), the Hertzsprung progression was quantified in terms of combinations of the low-order Fourier coefficients, viz.,

$$
R_{21}=A_{2} / A_{1}, \quad \phi_{21}=\phi_{2}-2 \phi_{1}, \quad \phi_{31}=\phi_{3}-3 \phi_{1} .
$$

In the present case, we lack sufficient data to employ the last of these.

Figure 1 displays a plot of $\phi_{21}$ versus period for the 11 stars in our sample. The resemblance of this plot to the 
TABLE 1

LIST OF STARS IN THE SURVEY

\begin{tabular}{|c|c|c|c|c|c|c|c|}
\hline $\begin{array}{c}\text { Star } \\
\text { Number }\end{array}$ & $\begin{array}{l}\text { Star } \\
\text { Name }\end{array}$ & Source & Period & $\begin{array}{l}\text { Amplitude } \\
\left(\mathrm{km} \mathrm{s}^{-1}\right)\end{array}$ & $\begin{array}{l}\text { Number of } \\
\text { Observations }\end{array}$ & $\begin{array}{l}\text { Order } \\
\text { of Fit }\end{array}$ & $\begin{array}{l}\text { Standard } \\
\text { Deviation } \\
\left(\mathrm{km} \mathrm{s}^{-1}\right)\end{array}$ \\
\hline 1. & SU Cas & 1 & 1.94933 & 24.7 & 135 & 4 & 1.88 \\
\hline $2 \ldots$ & $\mathrm{R} \operatorname{Tr} \mathrm{A}$ & 2 & 3.389287 & 31.6 & 27 & 4 & 1.68 \\
\hline $3 \ldots \ldots \ldots$ & $\mathrm{XY}$ Cas & 3 & 4.501697 & 34.2 & 47 & 4 & 0.956 \\
\hline $4 \ldots \ldots \ldots \ldots$ & V482 Sco & 2 & 4.52786 & 35.3 & 24 & 4 & 1.53 \\
\hline $5 \ldots \ldots \ldots \ldots$ & $\delta$ Cep & 4 & 5.36633 & 39.7 & 91 & 8 & 0.762 \\
\hline $6 \ldots \ldots \ldots \ldots$ & $S \operatorname{Tr} A$ & 2 & 6.32344 & 35.0 & 23 & 4 & 1.82 \\
\hline $7 \ldots \ldots \ldots$ & $\eta \mathrm{Aql}$ & 5 & 7.18372 & 42.0 & 31 & 4 & 1.83 \\
\hline $8 \ldots \ldots \ldots \ldots$ & S Sge & 6 & 8.38217 & 35.9 & 45 & 8 & 0.202 \\
\hline $9 \ldots \ldots \ldots$ & $\beta$ Dor & 7 & 9.84238 & 39.5 & 156 & 4 & 1.96 \\
\hline $10 \ldots \ldots \ldots \ldots$ & $\zeta \mathrm{Gem}$ & 8 & 10.1535 & 30.9 & 46 & 4 & 0.794 \\
\hline $11 \ldots \ldots \ldots$ & X Cyg & 9 & 16.3800 & 63.4 & 23 & 4 & 2.71 \\
\hline
\end{tabular}

SourcE.-(1) Abt 1959; Gieren 1976; Beavers 1979; $\tau=2,400,000$. (2) Gieren 1981; $\tau=2,444,000$. (3) Imbert 1981; $\tau=2,440,000$. (4) Shane 1958; $\tau=2,400,000$. (5) Wright 1899; $\tau=2,400,000$. (6) Herbig and Moore 1952 (Table 5); $\tau=0$, times as given in Table 5. (7) Applegate 1927; Stibbs 1955; $\tau=2,400,000$. (8) Campbell 1901; $\tau=2,400,000$. (9) Duncan $1921 ; \tau=2,420,000$.

TABLE 2

Fourier COEFFICIENTS $\left(A_{i}, \phi_{i}\right)($ where $i=1-4)$

\begin{tabular}{|c|c|c|c|c|c|c|c|c|c|c|c|}
\hline $\begin{array}{c}\text { Star } \\
\text { Number }\end{array}$ & $\begin{array}{l}\text { Star } \\
\text { Name }\end{array}$ & $t_{0}$ & $A_{0}$ & $A_{1}$ & $\phi_{1}$ & $A_{2}$ & $\phi_{2}$ & $A_{3}$ & $\phi_{3}$ & $A_{4}$ & $\phi_{4}$ \\
\hline $1^{\mathrm{a}}$ & SU Cas & 40,000 & $+1.34(-2)$ & 9.26 & 4.95 & 1.65 & 3.30 & $9.85(-2)$ & 3.06 & $2.60(-1)$ & 5.00 \\
\hline $2^{a}$ & R TrA & 421 & -13.33 & 10.32 & 1.36 & 4.44 & 2.54 & 1.86 & 4.37 & $5.80(-1)$ & 2.74 \\
\hline 3 . & $\mathrm{XY}$ Cas & 4010 & -42.07 & 14.98 & $6.68(-1)$ & 4.64 & 1.17 & 2.33 & 1.94 & 1.36 & 2.63 \\
\hline $4^{\mathrm{a}}$ & V482 Sco & 421 & +7.54 & 15.55 & 5.61 & 4.58 & 4.73 & 2.01 & 3.91 & 1.25 & 2.81 \\
\hline $5^{\mathrm{b}}$ & $\delta$ Cep & 6000 & -16.16 & 15.69 & 3.86 & 6.73 & 4.42 & 3.87 & 5.36 & 1.86 & 3.07 \\
\hline $6^{\mathrm{a}}$ & $S \operatorname{TrA}$ & 421 & +3.99 & 13.20 & $6.17(-1)$ & 5.79 & 1.39 & 1.93 & 2.61 & 1.14 & 2.81 \\
\hline 7. & $\eta$ Aql & 5500 & -14.46 & 16.16 & 2.17 & 8.14 & 4.72 & 3.31 & 1.13 & 1.58 & 3.11 \\
\hline $8^{\mathrm{b}}$ & S Sge & 0 & $+3.85(-2)$ & 14.31 & 5.65 & 7.59 & 5.80 & 1.86 & 5.42 & 1.49 & 5.40 \\
\hline 9 . & $\beta$ Dor & 5000 & $+1.44(-2)$ & 14.09 & $9.92(-1)$ & 5.00 & 3.84 & 2.38 & 4.71 & $3.71(-1)$ & $2.80(-1)$ \\
\hline 10 & $\zeta \mathrm{Gem}$ & 30,000 & +6.86 & 12.35 & 6.09 & 3.00 & 1.70 & 1.98 & 1.47 & $1.93(-1)$ & 3.03 \\
\hline $11^{\mathrm{a}}$ & X Cyg & 2000 & +9.43 & 27.00 & 5.32 & 5.39 & 4.58 & 3.35 & 2.33 & 2.56 & $8.96(-1)$ \\
\hline
\end{tabular}

${ }^{\mathrm{a}}$ Higher order coefficients $(i>2)$ may not be fully reliable.

${ }^{\mathrm{b}}$ Eight-order fit; see Table 3.

TABLE 3

FOURIER COEFFICIENTS $\left(A_{i}, \phi_{i}\right)$ (where $\left.i=5-8\right)$

\begin{tabular}{|c|c|c|c|c|c|c|c|c|c|}
\hline $\begin{array}{c}\text { Star } \\
\text { Number }\end{array}$ & $\begin{array}{l}\text { Star } \\
\text { Name }\end{array}$ & $A_{5}$ & $\phi_{5}$ & $A_{6}$ & $\phi_{6}$ & $A_{7}$ & $\phi_{7}$ & $A_{8}$ & $\phi_{8}$ \\
\hline & $\delta$ Cep & 1.13 & $7.21(-1)$ & $6.17(-1)$ & 4.54 & $3.99(-1)$ & 2.40 & $3.11(-1)$ & $6.13(-1)$ \\
\hline $8 \ldots$ & S Sge & $2.08(-1)$ & 5.28 & $4.39(-1)$ & 4.94 & $1.49(-1)$ & 4.80 & $2.21(-1)$ & 4.71 \\
\hline
\end{tabular}

corresponding one for the light curves in Simon and Lee (1981) is extremely strong. One sees the same moderate rise in $\phi_{21}$ between 4 and 8 days, followed by a rapid jump near 10 days and subsequent decline at longer periods. (Unfortunately, our present sample contains only one long-period star, X Cyg.)
In Figure 2 we plot the amplitude ratio $R_{21}$ versus period. Here, as in Simon and Lee, the scatter is considerably greater than that for $\phi_{21}$. Nonetheless, we may note a crude resemblance between the light and velocity data in the relative maximum which occurs before 10 days and the subsequent dropoff in the 10 day vicinity. 


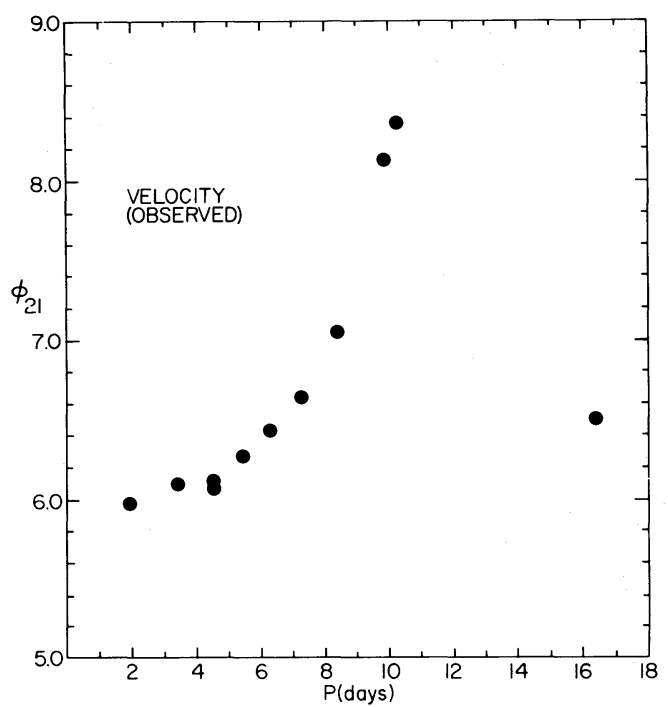

FIG. 1.-Phase difference $\phi_{21}=\phi_{2}-2 \phi_{1}$ vs. period

For the two stars with observations from more than one source, we might try to compare the values of $\phi_{21}$ and $R_{21}$ obtained by analyzing each source separately with the values coming from the combined data. In the case of SU Cas, unfortunately, the Fourier decompositions from individual data sets did not meet minimum criteria for reliability, as a result of inadequate phase coverage. On the other hand, for $\beta$ Dor, the larger of the two data sets (133 points) yielded values of $\phi_{21}$ and $R_{21}$ which differed by $\lesssim 3 \%$ from those of the combined set.

\section{DISCUSSION}

The qualitative correspondence between Cepheid light and velocity curves along the Hertzsprung sequence has long been known. In the present work this correspondence manifests itself in the quantities $\phi_{21}$ and $R_{21}$ determined by Fourier decomposition. In particular, one notices the sharp break at 10 days, characteristic of the period resonance $P_{2} / P_{0}=0.5$ (Simon and Schmidt 1976).

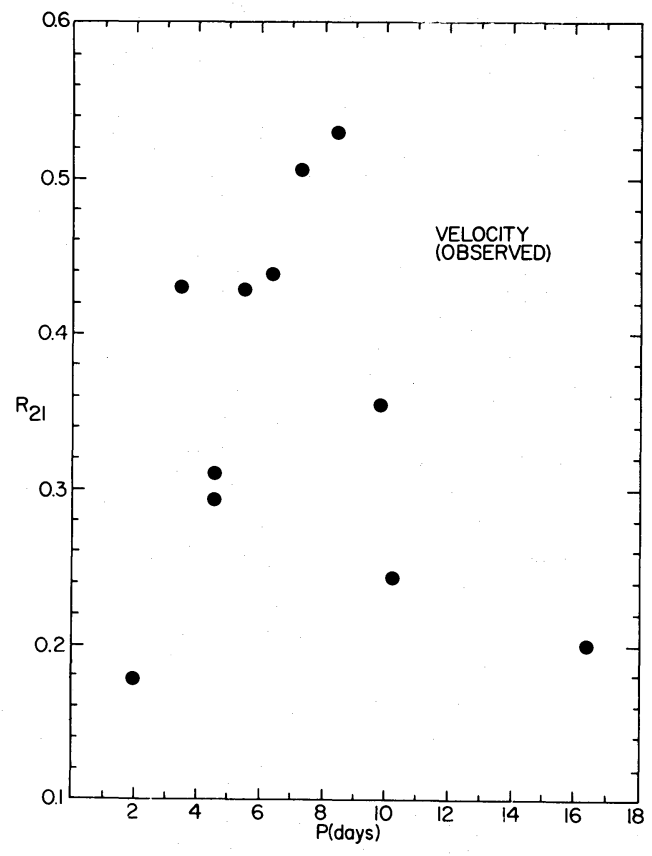

FIG. 2.-Amplitude ratio $R_{21}=A_{2} / A_{1}$ vs. period

It was suggested by Simon and Lee (1981) that Fourier decomposition ought to provide a useful medium for comparing the observed variations of Cepheids with those generated from hydrodynamic models. This comparison may be performed in either light or velocity. However, it is well known that the theoretical velocity curves are generally smoother than the light curves and display fewer numerical artifacts. Thus, from the theoretical side the match is better made in velocity. While the present investigation provides a preliminary basis for such a comparison, the situation would clearly be improved if accurate velocity curves could be determined for a larger sample of stars. A velocity study of Cepheids with periods between 10 and 16 days would be particularly useful to fill a serious gap in the present data. We recommend that such a study be undertaken.

The authors wish to thank A. S. Lee for aiding in this investigation. In addition, one of us (N. R. S.) is pleased to acknowledge support from the National Science Foundation under grant AST-8105064.
Abt, H. A. 1959, Ap. J., 130, 1021 Applegate, D. 1927, Lick Obs. Bull., 13, 12. Beavers, W. I. 1979, private communication. Campbell, W. W. 1901, Ap. J., 13, 90. Duncan, J. C. 1921, Ap. J., 53, 95. Gieren, W. 1976, Astr. Ap., 47, 211. 1981, Ap.J. Suppl., 46, 287.

\section{REFERENCES}

Herbig, G. H., and Moore, J. H. 1952, Ap. J., 116, 348.

Imbert, M. 1981, Astr. Ap. Suppl., 44, 319.

Shane, W. W. 1958, Ap. J., 127, 573.

Simon, N. R., and Lee, A. S. 1981, Ap. J., 248, 291.

Simon, N. R., and Schmidt, E. G. 1976, Ap. J., 205, 162.

Stibbs, D. W. N. 1955, M.N.R.A.S., 115, 363.

Wright, W. H. 1899, Ap. J., 9, 59.

Norman R. Simon and Terry J. Teays: Behlen Laboratory of Physics, University of Nebraska, Lincoln, NE 68588 